Résumés des conférences et travaux

\title{
Études scandinaves
}

\section{Alessia Bauer}

\section{OpenEdition \\ Journals}

Édition électronique

URL : https://journals.openedition.org/ashp/4489

DOI : $10.4000 /$ ashp.4489

ISSN : 1969-6310

Éditeur

Publications de l'École Pratique des Hautes Études

\section{Édition imprimée}

Date de publication : 1 septembre 2021

Pagination : 302-305

ISSN : 0766-0677

\section{Référence électronique}

Alessia Bauer, «Études scandinaves », Annuaire de l'École pratique des hautes études (EPHE), Section des sciences historiques et philologiques [En ligne], 152 | 2021, mis en ligne le 14 juin 2021, consulté le 14 juin 2022. URL : http://journals.openedition.org/ashp/4489 ; DOI : https://doi.org/10.4000/ashp.4489 


\title{
ÉTUDES SCANDINAVES
}

\author{
Directrice d'études : $\mathrm{M}^{\mathrm{me}}$ Alessia BAUER
}

Programme de l'année 2019-2020 : I. Introduction à la runologie. - II. Introduction au vieux norrois. - III. Outils collectifs de la recherche.

\section{Introduction à la runologie}

Les conférences de l'année ont porté sur l'écriture runique, qui a été abordée à la fois sous l'angle de sa relation avec l'alphabet latin et sous celui de la fonction qu'elle revêt au sein d'une culture essentiellement orale.

Les conférences des premiers mois ont été consacrées à une introduction générale aux caractéristiques propres à ce système d'écriture, qui diffère des alphabets méditerranéens à partir desquels il a été néanmoins créé, à savoir les alphabets latin, grec ou encore vénétiques du Nord de l'Italie.

Les inscriptions runiques s'avèrent une source de grande importance pour l'histoire de la langue. Elles constituent en effet les plus anciennes attestations des langues germaniques et, comme telles, nous offrent un riche matériau de comparaison, tout fragmentaire qu'elles soient, avec ce qui est sans cela seulement présumé par les linguistes sur la base de reconstructions. Parfois, il suffit d'un nouveau texte pour réfuter ou bien confirmer une des thèses proposées par ces derniers, comme cela s'est produit suite à la récente découverte à Frienstedt (Thuringe, Allemagne) d'un peigne portant une très brève inscription runique. Jusqu'à cette date, on considérait la « langue runique » de la période 150-500 apr. J.-C. comme une forme commune de germanique nord-occidental, une sorte de continuum linguistique ${ }^{1}$, dans la mesure où les inscriptions connues ne permettaient pas de percevoir de claires distinctions entre le germanique du Nord et le germanique occidental avant l'an 400. Or l'inscription du peigne de Friensted, qui date du milieu du III $^{\mathrm{e}}$ siècle apr. J.-C., recèle une terminaison différente de celles du germanique du Nord, de sorte que désormais il est avéré qu'il est préférable de fixer le début de la division entre les deux branches du germanique dès le $\mathrm{III}^{\mathrm{e}}$ siècle $^{2}$.

Bien qu'il soit très important, l'aspect linguistique n'est toutefois pas le seul qui mérite notre attention. Les inscriptions runiques fournissent en outre des sources inestimables pour les investigations relatives à l'histoire des mentalités. Il est en effet surprenant que, dans une culture orale, comme l'était celle de la société germanique, se

1. Hypothèse proposée encore récemment par Hans-Frede Nielsen, The Germanic Languages. Origins and Early Dialectal Interrelations, Tuscaloosa, 1989, ainsi que dans sa contribution « The Early Runic Language of Scandinavia: Proto-Norse or North-West Germanic?», dans Zentrale Probleme bei der Erforschung der älteren Runen: Akten einer internationalen Tagung an der Norwegischen Akademie der Wissenschaften, J. O. Askedal (éd.), Francfort-sur-le-Main, 2010, p. 95-114.

2. À ce sujet, voir Robert Nedoma, « Urnordisch -a im Nominativ Singularis der maskulinen n-Stämme », dans Papers on Scandinavian and Germanic Language and Culture, Odense, 2005, p. 155-191, ainsi que Michael Schulte, Urnordisch: Eine Einführung, Vienne, 2018 (Wiener Studien zur Skandinavistik 26). 
soit subitement fait ressentir le besoin d'écriture. L'étude de ces textes peut donc améliorer notre compréhension de cette société. À ce titre, nous nous sommes notamment posé la question de savoir comment s'est développée la culture écrite (ce qu'en anglais on désigne par literacy et que, par un néologisme français, on appelle désormais « litératie ») dans les cultures (nord-)germaniques et quel était au Moyen Âge le rapport entre les différents types d'écriture, à savoir entre l'écriture latine et l'écriture runique.

Étant donné que les inscriptions runiques - comme d'ailleurs aussi les manuscrits - constituent des attestations uniques, il faut les considérer dans leur intégralité, à savoir dans l'ensemble de leurs systèmes sémiotiques, et non uniquement comme des documents de communication verbale; pour les comprendre pleinement, il est donc également nécessaire de tenir compte de leur contexte.

Au sein de la société germanique, l'écriture incarnait un moyen mis à la disposition d'une élite aristocratique, laquelle utilisait les textes écrits à la fois comme une marque de prestige et comme un instrument de pouvoir. Dans cette perspective, nous avons proposé une interprétation de la pierre runique de Jelling 2 (au Danemark) comme un symbole visible et tangible du pouvoir du roi Haraldr Gormsson «à la dent bleue », ainsi que comme un moyen d'intégrer son royaume au sein de la civilisation chrétienne de l'Europe continentale. En effet, le monument, qui date du milieu $\mathrm{du} \mathrm{x}^{\mathrm{e}}$ siècle, montre la première image du Christ en croix. En regardant la première face de cette pierre runique, on s'aperçoit également que l'écrit est encadré par des éléments ornementaux qui rappellent assez clairement la décoration de l'enluminure ottonienne et peut-être aussi les manuscrits celtiques ou anglo-saxons. Cela conduit à penser qu'ici s'est produite une transposition médiatique qui a adapté la mise en page des livres - à cette époque encore inconnus au Nord de l'Europe - à un monument épigraphique. Les systèmes sémiotiques dans lesquels s'inscrit le maître des runes interagissent donc pour délivrer un message conjoint. Cette pierre runique partage la fonction des monuments commémoratifs, mais elle contribue encore plus à l'affirmation du pouvoir séculier du roi vivant.

Il est une autre région dans laquelle on peut s'aviser de l'intérêt que présentent les runes au-delà de la perspective proprement linguistique : il s'agit de la province runique située au sud de l'Allemagne, qui constitue l'un des axes de recherche de la directrice d'études. Dans cette région, les runes apparaissent soudain vers 520 pour disparaître presque complètement cent ans plus tard. Le corpus est composé d'une centaine d'inscriptions, toutes relevées sur de petits objets (broches, armes, accessoires, etc.). Il ne semble pas possible d'identifier l'origine du phénomène ni les intermédiaires auxquels on a fait appel; le corpus, qui contient des textes (très) brefs, témoigne en général d'un manque d'expérience dans l'exécution. Le fait que plusieurs inscriptions ne puissent pas être interprétées d'un point de vue linguistique nous a conduit à postuler que dans ce cadre l'écriture était investie d'une valeur en soi, et qu'il s'agissait d'une communication dont le contenu lexical était secondaire (une sorte de symbole de statut, éventuellement pour marquer l'appartenance à une classe, à une communauté spécifique) ${ }^{3}$. Puisque les objets runiques ont été trouvés dans des tombes de l'aristocratie alémanique, on a pu les situer dans un contexte

3. À cet égard, la directrice d'études a rédigé une contribution intitulée «"Mind-body-technology" and function: the multiple components of runic production » dans le cadre d'un projet élaboré par une col- 
socio-historique précis et en déterminer la fonction. On observe alors la différence entre la mise en œuvre d'inscriptions « invisibles » sur la face intérieure des broches relevant de la communication privée, adressées principalement à des femmes, et d'autres visibles sur la face extérieure des objets destinés à des hommes.

La transformation médiatique (de l'oralité au mot écrit, puis des runes à l'alphabet latin) impliqua un changement radical dans la production des textes. Ce qui s'avère particulièrement digne d'intérêt, n'est pas alors seulement la forme purement linguistique ou littéraire qui se fait jour, mais également la fonction et l'ancrage des textes dans le contexte socio-historique, ainsi que leur réception au cours des siècles. La fascination pour l'interaction entre les médias et les modalités de transmission textuelle a constitué une perspective de travail tout au long des conférences.

\section{Introduction au vieux norrois}

Parallèlement aux conférences, la directrice d'études a dispensé pendant l'année des cours d'initiation au vieux norrois à raison de deux heures hebdomadaire supplémentaires.

Le vieux norrois était la langue parlée par les peuples du Nord (au Danemark, en Norvège, en Suède, en Islande ainsi que dans les colonies scandinaves) à partir de l'âge des Vikings (de 793 à 1066 selon la périodisation conventionnelle) jusqu'au milieu du Moyen Âge (début $\mathrm{XV}^{\mathrm{e}}$ siècle). En particulier, il existe, dans sa variante qu'est le vieil islandais, une très riche production littéraire, transmise dans des manuscrits médiévaux, qui donna vie à des genres inconnus ailleurs, notamment les sagas ou la poésie scaldique.

Ce cours de niveau débutant a eu pour objectif l'apprentissage de la structure du vieux norrois, en particulier de ses caractéristiques phonologiques et morphologiques, afin de permettre une lecture aisée des sources en langue originale.

La méthode d'enseignement a consisté à montrer à un public francophone la structure des langues germaniques en général et des langues nordiques en particulier. En ce qui concerne les outils et les supports, après une phase initiale entièrement centrée sur la morphologie de la langue, dans laquelle ont été surtout utilisés des livres de grammaire pour identifier et reproduire des mots et des structures grammaticales, nous sommes passés à une phase plus avancée de lecture et traduction de sources originales.

\section{Outils collectifs de la recherche}

Au sein du programme de master «Civilisations, cultures et sociétés ", la directrice d'études a participé aux modules des premier et deuxième semestres appelés " Outils collectifs de la recherche » en donnant deux conférences.

La conférence du premier semestre était intitulée "L'arrivée de l'écriture au Nord : les runes, les manuscrits, les textes produits et transmis ». Elle visait à donner succinctement un aperçu du spectre des études scandinaves médiévales, en mettant l'accent sur la mise par écrit de la langue.

lègue norvégienne, Petrine Vinje (Universitet i Oslo), dont l'achèvement est prévu vraisemblablement au cours de l'année 2021. 
La conférence du second semestre était intitulée «Les sources pour l'étude de la culture nordique ancienne et médiévale ». Elle a porté sur la présentation des sources écrites médiévales qui sont toutes assez tardives en comparaison des littératures européennes, en raison de l'introduction tardive de l'écriture. Avant le $\mathrm{XI}^{\mathrm{e}}$ siècle, il est donc nécessaire de prendre en considération d'autres sources, à savoir des sources iconographiques et des inscriptions runiques. Même s'il ne s'agit pas de textes narratifs, images et inscriptions nous donnent un aperçu de cette culture nordique - à l'époque encore orale - et de son extension. 